\title{
DUAL DEGREES: TWICE AS GOOD?
}

\author{
D. Cobham \\ University of Lincoln (UNITED KINGDOM)
}

\begin{abstract}
Transnational Education (TNE), i.e. the delivery of programmes and awarding of qualifications by one University at a campus or with a partner institution in a different country, is becoming increasingly popular. Factors affecting this include: changing demographics whereby diminishing numbers of eligible students are applying to study at the home institution; political factors such as Brexit or changes in immigration laws; financial factors such as the desire to increase revenue or to diversify sources of external income; brand building; networking etc.

Typically TNE is delivered at a branch campus of the home university located in the country of delivery, or in partnership with a local higher education provider based in another country. The models for TNE include franchised delivery, validated programmes, joint or dual degrees twinning arrangements.

This paper adopts a case study approach to investigate one particular model for TNE namely the dual degree. The paper considers a novel implementation of a dual degree whereby the curriculum followed by the students is the locally validated programme rather than the curriculum of the home institution. In order to make the award, the international partner curriculum has been mapped closely against that of the home institution. The mapping is carried out at a detailed level in order to establish that both the high level programme outcomes and the lower level module (sometimes called course) outcomes of the home institution's programmes are all appropriately addressed by those of the international partner institution's curriculum. Coverage is then established by ensuring that on every piece of assessed work, it is clearly identified which learning outcomes of each institution are being assessed. Application of a mapping matrix, developed at the approval phase, by assessment setter, moderator and external examiner is carried out. On the basis of the correct application of that mapping, the overall coverage of outcomes is ensured and the award of the home institution is conferred on those students who successfully complete the award at the partner institution.
\end{abstract}

The case study reveals an interesting research question namely whether a programme of study is more than just the summation of its constituent learning outcomes or "is the whole greater than the sum of its parts"? Consideration is made whether there a level of decomposition or deconstruction of a programme that results in the essence of that programme being lost.

The paper concludes that by satisfying the functional constraints of the mapping, in combination with a carefully constructed system of mutual partner support, an appropriate and quality student experience can be achieved that both respects the local curriculum and delivers the home institution's award.

Keywords: Dual degree, transnational education.

\section{INTRODUCTION}

Higher education institutions have for many years engaged in different variants of Transnational Education (TNE). The Council of Europe defines TNE as, "all types of higher education study programs, or sets of courses of study, or educational services (including those of distance education) in which the learners are located in a country different from the one where the awarding institution is based." [1].

The benefits to students of following a dual degree are well documented [2]. Typical reasons for enrolling onto such a programme include: seeking international educational experience; the affordability compared to studying in another country; increasing salary and career prospects etc.

In terms of TNE hosting countries, Malaysia then Singapore then China have the greatest number of student participants [3]. The range of subjects delivered through TNE is very board; a cursory glance at the literature quickly illustrates the variety: Mechatronics [4], Social Work [5], Art History [6], High Performance Computing [7], Pharmacy [8]. 
Table 1. Popular models for TNE (based on [9], [10], [11])

\begin{tabular}{|c|c|c|c|c|}
\hline & Definition & $\begin{array}{l}\text { Quality } \\
\text { Assurance }\end{array}$ & $\begin{array}{l}\text { Teaching takes } \\
\text { place at }\end{array}$ & Award by \\
\hline $\begin{array}{l}\text { Branch } \\
\text { campus }\end{array}$ & $\begin{array}{l}\text { A foreign sending } \mathrm{HEI} \\
\text { offers academic programs } \\
\text { through their own satellite } \\
\text { campus located in host } \\
\text { country. }\end{array}$ & $\begin{array}{l}\text { QA dependent } \\
\text { on national } \\
\text { regulations of } \\
\text { both host and } \\
\text { sending } \\
\text { countries. }\end{array}$ & $\begin{array}{l}\text { Branch campus } \\
\text { faculty in host } \\
\text { country }\end{array}$ & $\begin{array}{l}\text { Qualification and } \\
\text { curriculum by } \\
\text { offered sending } \\
\text { foreign se } \\
\text { HEI }\end{array}$ \\
\hline Franchise & $\begin{array}{lr}\text { A private independent } \\
\text { HEl/provider offers a series } \\
\text { of franchised academic } \\
\text { programs from different } \\
\text { foreign } & \text { sending } \\
\text { HEl/providers. } & \\
\end{array}$ & $\begin{array}{l}\text { QA dependent } \\
\text { on national } \\
\text { regulations of } \\
\text { host and sending } \\
\text { countries. }\end{array}$ & $\begin{array}{l}\text { Host country } \\
\text { HEI }\end{array}$ & $\begin{array}{l}\text { Qualification and } \\
\text { curriculum by } \\
\text { offered s bending } \\
\text { foreign sn } \\
\text { HEls }\end{array}$ \\
\hline Joint award & $\begin{array}{l}\text { Partners devise one } \\
\text { collaborative programme } \\
\text { with periods of study at } \\
\text { each location leading to } \\
\text { one award. }\end{array}$ & $\begin{array}{l}\text { QA is normally } \\
\text { the responsibility } \\
\text { of each partner } \\
\text { HEI. }\end{array}$ & $\begin{array}{l}\text { Alternate } \\
\text { delivery by } \\
\text { foreign sending } \\
\text { and host country } \\
\mathrm{HEI}\end{array}$ & $\begin{array}{l}\text { A joint degree } \\
\text { program offers } \\
\text { one qualification } \\
\text { with badges of } \\
\text { both sending and } \\
\text { host HEls on } \\
\text { certificate. }\end{array}$ \\
\hline $\begin{array}{l}\text { Dual/double } \\
\text { award }\end{array}$ & $\begin{array}{l}\text { Partners collaborate to } \\
\text { develop programmes } \\
\text { which lead to awards made } \\
\text { by both }\end{array}$ & $\begin{array}{l}\text { QA is normally } \\
\text { the responsibility } \\
\text { of each partner } \\
\mathrm{HEI} \text {. }\end{array}$ & $\begin{array}{lr}\text { Usually host } \\
\text { country HEl, } \\
\text { sometimes both }\end{array}$ & $\begin{array}{l}\text { A double degree } \\
\text { program offers } \\
\text { two } \\
\text { qualifications- } \\
\text { one certificate/ } \\
\text { qualification from } \\
\text { each partner }\end{array}$ \\
\hline Twinning & $\begin{array}{l}\text { A foreign sending } \mathrm{HEl} \\
\text { offers } \\
\text { program(s) through a host } \\
\text { country HEl. }\end{array}$ & $\begin{array}{l}\text { QA dependent } \\
\text { on national } \\
\text { regulations of } \\
\text { host and sending } \\
\text { countries }\end{array}$ & $\begin{array}{l}\text { Host country } \\
\text { HEI r then } \\
\text { complete at } \\
\text { foreign sending } \\
\text { HEl } \\
\end{array}$ & $\begin{array}{l}\text { Foreign sending } \\
\text { HEI provides } \\
\text { curriculum and } \\
\text { awards } \\
\text { qualification }\end{array}$ \\
\hline Distance & $\begin{array}{l}\text { Foreign sending distance } \\
\text { education provider offers } \\
\text { academic programs } \\
\text { directly to host country } \\
\text { students. }\end{array}$ & $\begin{array}{l}\text { QAA from foreign } \\
\text { sending country. }\end{array}$ & $\begin{array}{l}\text { Usually } \\
\text { delivered } \\
\text { without } \\
\text { geographic } \\
\text { attendance } \\
\text { requirement. } \\
\text { Occasionally } \\
\text { some face-to- } \\
\text { face support in } \\
\text { approved study } \\
\text { centres. }\end{array}$ & $\begin{array}{l}\text { Qualification, } \\
\text { curriculum, and } \\
\text { QA offered by } \\
\text { foreign sending } \\
\text { HEI. }\end{array}$ \\
\hline
\end{tabular}

There are many reasons for HE institutions to engage in TNE; these include:

- to internationalise the curriculum and provide international experiences for its students [2]

- to build the institution's international brand and prestige in order to widen its sphere of influence in a territory [12]

- to address the push from overseas governments to attract overseas talent and also to increase the provision of higher education where its capacity is locally constrained [13]

- in make their graduating students more employable 
- to increase and diversify income

Key decisions that need to be taken in embarking on a TNE partnership include the structure/organization of the collaboration, the location, the scale and scope, the reputation and the brand of the partners, the financial model etc. All these decisions need to be taken mindful of the risks involved.

TNE can take many different forms. Table 1 shows some of the more popular models. In this table a distinction is made between the foreign sending $\mathrm{HEI}$ (often the provider of the curriculum) and the host country HEI (invariably where most of the study takes place).

As mentioned above, the key decisions around organization are intrinsically linked to elements of risk. Healy [3] provides an analysis of the degree of risk in different forms of TNE partnership. He points out that risk of reputation damage rises as more autonomy in quality assurance migrates towards the host country partner. This is captured in Fig. 1.

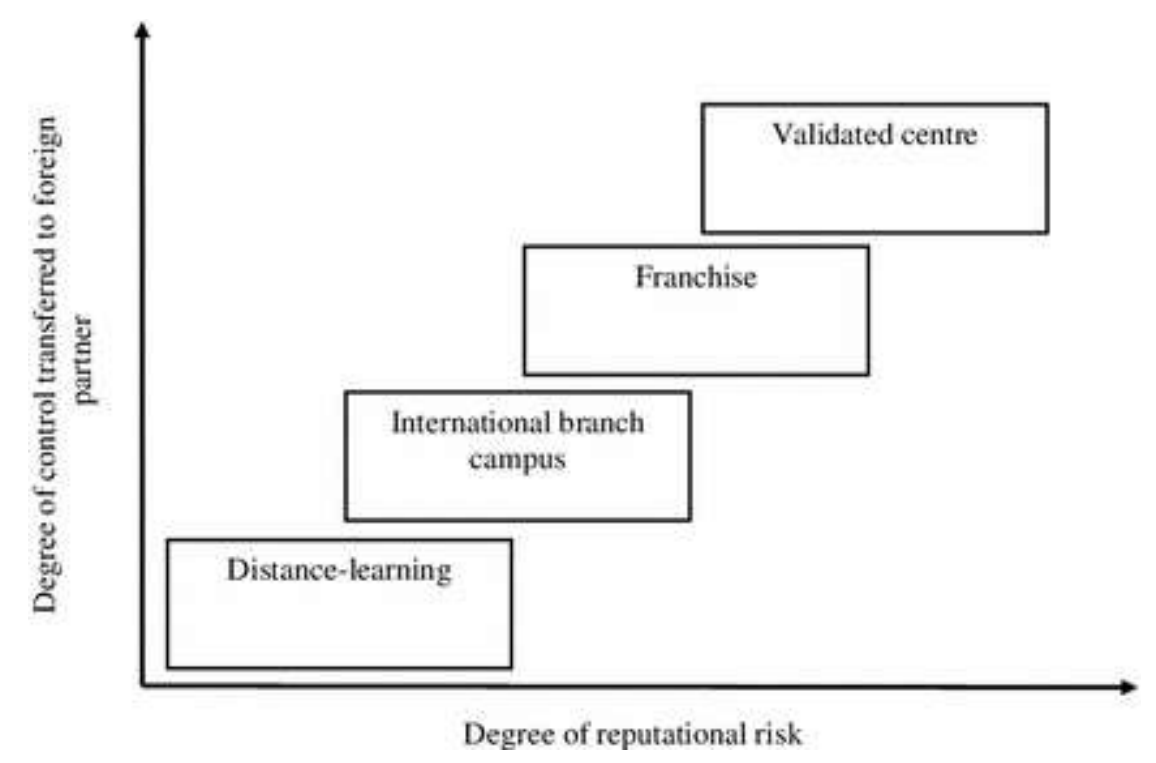

Figure 1. Reputational risk vs autonomy in quality assurance (from [3])

In addition, the diversity in the participating stakeholders might mean that ethical issues introduce further challenges and potential risks. Wilkins [14] identifies civil liberties and academic freedom as two such issues that might require addressing in formulating a TNE partnership.

In this case study careful regard was given to the type of partnership to be adopted; the desire to promote autonomy and mutually supportive growth and development, supported by an analysis and mitigation of the inherent risks, led to a dual degree approach being chosen.

\section{METHODOLOGY}

A case study approach has been adopted in carrying out this research. An interesting exposition of the benefits of using case study research was proposed by Cronin [15]. This described the bringing together of a range of review methods including observations, interviews and documents to facilitate systematic and rigorous analysis in sectors such as nursing and education. At this early stage in the project a full set of quantitative data to process and evaluate does not yet exist. The focus here is therefore on qualitative research following the principles outlined by Silverman [16] that this should be concerned with social practices as much as about experience and that it should be a rigorous and credible enterprise. Observations of assessment procedures, interviews with key staff and inspections of documents including regulations and procedures were all carried out. 


\section{RESULTS}

\subsection{Background to the Case Study}

University College "K" (hereafter referred to as KUC) is a private provider of Higher Education in Malaysia. It provides programmes in a wide range of subjects. It is rated as a 6 Stars out of 6 college on the Malaysian MyQuest evaluation system and is on a trajectory to achieve full University status. Part of that journey involves the enhancement of its internationalisation strategy including building up international partnership activities.

University "L" (hereafter referred to as UL) is a UK public University. Although one of the newer Universities it has achieved a great deal in its relatively short history; it is currently ranked 43 out of 131 UK Universities, with success in producing world class research in many fields and an excellent teaching and learning record: it is one of the $20 \%$ of UK Higher Education Institutions that have been awarded a TEF Gold rating and it was recently rated 23 out of 116 institutions for student experience. Like many Universities it has a strategic goal to internationalise the student experience, to increase staff and student mobility and to widen its international reach and reputation.

In 2016 a decision was taken by both institutions formulate a partnership together and to develop a set of dual degree programmes. The decision to adopt dual degrees as the preferred TNE format was based on several factors:

- it allows for a greater degree of separate curriculum development

- it allows for more flexibility in setting and modifying assessments and curriculum

- it facilitates mutual growth and development giving more equal status to the participants in the partnership

\subsection{The design approach}

The design approach taken in establishing the portfolio of dual degrees was based on a uni-directional model; that means that a student attends, studies and is assessed in a programme delivered at KUC by their staff and upon successful completion she or he is made an award by KUC and also by UL. To date it hasn't been designed for a UL student to graduate with a dual award made by KUC (although see section below: Student Mobility).

(Note: in the following sections, the term "module" has been used to describe the fundamental curriculum building block in the delivery of a programme of higher education. Sometimes called a course, a module is a self-contained block of study, titled and managed by a named coordinator, that typically comprises $15-25 \%$ of the content of each year/level of study.)

To create the dual degree it was decided to adopt a mapping approach whereby:

- pairs of programmes were located, one from each institution, where a dual award was considered to be possible

- the module learning outcomes of each programme were compared

- it was noted where coverage of each UL module learning outcome could be identified with an equivalent KDU module level learning outcome(s)

- programme level outcomes of each programme were checked for similarity

- if all UL module level learning outcomes could be shown to be satisfied by one or more KUC module level outcomes then a dual award was considered a viable proposition and was put forward for formal accreditation

In carrying out the mapping it is important to note that:

- the mapping process was carried out mindful of the level at which the module outcomes were addressed and assessed by each institution

- because of differences in curriculum construction by each institution, it was not possible to undertake the mapping on a module-to-module basis. In a small number of cases, module learning outcomes were covered in Year 1 at one institution but in Year 2 at the other. In these cases, in order for a mapping to be identified, pre- and co-requisite knowledge was checked to ensure a logical progression through the curriculum was preserved

- in all cases of UL module mappings at the final Year/Level, a match was required at the same level on the KUC programme; although it was felt that this requirement could be 
relaxed in earlier years of study, it was considered more important to satisfy the level requirements of final year module outcomes given the effect on degree classification etc.

\subsection{The contribution of constructive alignment}

The mapping process was underpinned at both institutions with adherence to the principles of constructive alignment [17]. Pioneered by Biggs [18] [19], constructive alignment refers to the linkage within a programme of study starting from the programme outcomes, through to the modules and their learning outcomes and then through to the teaching and assessment activities that are devised to cover and fulfil those module outcomes. Students learning is thereby constructed from this experience, and the alignment ensures that the higher-level programme outcomes are demonstrably satisfied by the learning and, more particularly, the assessment of learning that takes place. Constructive alignment is now widely adopted in the UK and many other education systems, often being systematically incorporated into the curriculum and assessment procedures and processes and sometimes being enforced through information systems that have been designed with the philosophy of constructive alignment at their core [20].

The outcome of the mapping process can best be pictured as a matrix or table with the UL modules and their constituent learning outcomes listed on one axis and the KUC modules and their constituent learning outcomes listed on the other. A "tick" in a cell of this table will be at the intersection of a module learning outcome from each programme and effectively states that this UL module learning outcome can potentially be evidenced by demonstrating competence in the associated module learning outcome in the KUC curriculum. Coverage of every UL module learning outcomes in this way indicates that by satisfactorily completing the KUC programme a student will also have satisfied every learning outcome of the UL programme; a UL dual degree can therefore be awarded.

Once the curriculum mappings had been established, the programmes were put through a normal quality assurance approval procedure. This considered: the delivery centre, human and other resources, library and other student learning support etc.

\subsection{Respecting curricula}

One of the main criticisms of franchise and twinning arrangements is the perpetuation of what some refer to as a colonialist approach to international partnerships [21]. Traditionally Universities, largely from the West, have set up a presence or partnership, largely in the East, and delivered their curriculum promoted on the basis of its supposed superiority to the local alternative. This take-it-or-leave it approach does have the advantage of enforcing consistency of standards at the delivering institution, but it does little to encourage autonomy, growth and mutual respect between the partners. Whilst a dual award implies comparability in syllabus and approach between partners, it can also provide a degree of flexibility. In particular, it allows the overseas partner to maintain and develop their own content and style. This inherent respecting of the local curriculum can create an environment that is more conducive to mutual development and advancement for both partners. This approach was considered highly beneficial in this particular case and a major reason why a dual award created by mapping between curricula was adopted.

\subsection{Delivery and assessment issues}

As discussed above, the adoption of a dual degree based on a mapping of outcomes rather than a franchise arrangement does create a higher requirement to demonstrate equivalence of content coverage and achievement of standards. Under a franchise, the curriculum content and its accompanying assessments are usually identical for both partners. Under the dual degree mapping adopted in this case, the alignment from programme outcomes through module outcomes into assessments is established but is not so transparent. This is partly due to the lack of a direct linkage at the module-to-module level: outcomes in a module at one institution might be distributed across more than one module (and sometimes level) at the other.

To address this disparity, an adjustment to the assessment process was applied. Under this adjustment, each assessment front sheet was required to indicate not only the KUC module learning outcomes that were to be assessed, but also which UL module learning outcomes were expected to be demonstrated. The effort and care invested in designing the mapping matrix referred to above becomes crucial here. Because linkages between outcomes were located and assigned extremely carefully, the matrix shows clearly which outcomes need to be covered across the assessment diet for the module. This is of crucial 
importance to the tutor (in devising the assessment appropriately), to the student (to understand the requirements of the task) and to the external examiner (to be assured that all learning outcomes are being assessed). An interesting sub-question arises here in that the requirements of two programmes need to be satisfied [22]. To reconsider the title of this paper, are dual degrees twice the effort?

In most cases the linked outcomes will be sufficiently similar not to require any amendment to the task or additional effort on the part of the student. In a limited number of cases a pair of linked outcomes may differ very slightly. In these cases the tutor setting the assessment can often include a subtle flavouring to the task to ensure that both outcomes are satisfied. In a very small number of cases there is a requirement for the student to undertake an additional task or activity to evidence the required coverage. This is a small additional workload about which students are made aware on initially enrolling onto the dual degree.

\subsection{Quality assurance issues}

In any comparison of academic provision, the distinction between academic quality (the nature of the learning experiences of students) and the academic standards (the level of achievement against clearly articulated outcomes) is important to understand. This is even more significant in the case of international partnerships. Sharpe [23] focuses on this this differentiation by querying which of the partner institution's, or nation's, standards are applied; it may be desirable or even necessary to agree and impose a common set of standards. He goes on to point out that learning environments and cultural issues might lead to significant differences in the quality of learning experience between different international providers and an attempt to impose a common learning experience across those providers might actually do harm rather than result in benefit.

To ensure compatibility in standards between pairs of programmes that were brought together in dual degrees in the case study, it was decided to appoint external examiners whose responsibilities straddled the programmes at both institutions. The contract of employment included responsibilities to:

- approve assessment tasks set by tutors at KUC ensuring that their module learning outcomes were appropriately covered

- ensure that KUC assessment tasks also covered the linked UL learning outcomes as indicated by the mapping matrix

- inspect samples of KUC student submissions of assessments to establish coverage of all learning outcomes at the appropriate standard compare samples of KUC student assessments with equivalent samples of UL student assessments to ensure comparability of standards across institutions

In addition, a programme of collaborative activities involving staff and students was devised. This included: student mobility programmes, staff exchange, staff development and enhancement activities, guest lectures, joint student learning activities etc. This coming together of participants was introduced in part to share best practice and thereby improve the quality of the provision for both partners.

\subsection{Evaluation of student performance}

The dual degree scheme is in its early stages. Students on programmes ranging from media production, public relations, business, accountancy and computing subjects have been recruited onto the scheme. At enrolment, students are given the choice either to enrol onto a single award offered by KUC or to enrol onto the dual award. To date a clear majority (100\% in some subjects) have elected to take the dual degree route. Students are taught together regardless of their decision. Those taking the single award receive assessments which only indicate the learning outcomes of the KUC programme.

At the time of writing KUC students are studying on dual degree programmes at Year 1 and Year 2 and the initial cohort has just reached Year 3 of the programme and are currently completing their first semester at that level. An analysis of student progression rates for KUC students shows that they are comparable to those achieved by UL students taking the equivalent programme in an on-campus, single degree format. External examiner reports provide further evidence of coverage of the required learning outcomes and comparability of standards between programmes offered by each institution. As cohorts complete all three years of study it will be possible to undertake further statistical analysis. 


\subsection{Student mobility}

One of the significant benefits of forming an educational partnership of this kind is the potential to offer opportunities for student and staff exchange or study abroad schemes. Whilst student mobility is not the focus of this paper, it is worth noting that credit for study on one programme can easily be transferred across to another. This opens up the possibility for short summer programmes, single semester or whole-year study abroad schemes for students at either institution. In these situations, the transfer of credit does work bi-directionally ensuring that all students within the partnership can benefit from undertaking these periods of mobility.

\section{CONCLUSION}

The pervasive underpinning of constructive alignment provides the essential glue that holds together this form of dual degree. Under constructive alignment, the KUC programme outcomes are satisfied by a set of modules each of which contain a set of module learning outcomes. These outcomes inform the teaching process, and performance in these outcomes is demonstrated through the assessments that are undertaken. At the point of assessment, a further set of module level learning outcomes (those from the UL dual degree) are identified; assessment of these is also ensured. The successful coverage of this set UL outcomes demonstrates coverage of all the modules that comprise the UL programme and therefore that the UL programme outcomes have been met.

An interesting question therefore arises: can the constituent parts of the programme of one institution be decomposed, reassembled in a different format, then recomposed to satisfy the requirements of the programme of another institution. This is the basis on which the dual award in the case study is made. In a purist sense, success in completing a programme can be evidenced by demonstrating success in the programme's learning outcomes. From a QA perspective, external examiners focus largely on this quantifiable evidence to formulate a view about appropriateness of standards. There are, however, other, less tangible aspects of what it means to be a graduate of a particular programme - these are the aspects that constitute the quality of the provision as opposed to the standards achieved. There may, for example, be an ethos that is informed by the mission of the host institution, or particular approaches that are adopted by the teaching team. One of the attractions of this dual degree form of collaborative delivery is the freedom for each team to develop separately and for each to respect the style and approach of the other. However, it is a mutually supportive partnership; as the institutions work together and people get to know each other better there are many and increasing opportunities for staff and students of one institution to work with staff and students of the other. This co-working and sharing of ideas and approaches is permeating the teaching and learning and in this way elements of best practice, including many of these intangible aspects of each other's programmes, are becoming more evident. This is allowing the essence of the programme that transcends the building blocks of learning outcomes to permeate the learning experience and to ensure that graduates of a dual degree genuinely have a sense of graduating with much more than just a second transcript of results and award certificate. Whether a dual degree is twice as good remains debatable, but it is hoped that students of this particular case study will appreciate and benefit from having graduated from two different institutions and that they have been shaped by the ethos of two rather than just one.

\section{ACKNOWLEDGEMENTS}

My thanks go out to the staff of both contributors to this partnership who have worked tirelessly to provide novel, vibrant and attractive educational opportunities for students and for staff at both institutions.

\section{REFERENCES}

[1] Council of Europe, "Code of Good Practice in the Provision of Transnational Education," Council of Europe , 1 January 2002. [Online]. Available: https://www.coe.int/t/dg4/highereducation/ Recognition/Code\%20of\%20good\%20practice_EN.asp\#TopOfPage. [Accessed 8 May 2018]. 
[2] S. Culver, I. Puri, G. Spinelli, K. DePauw and J. Dooley, "Collaborative Dual-Degree Programs and Value Added for Students: Lessons Learned Through the Evaluate-E Project," Journal of Studies in International Education, vol. 16, no. 1, pp. 40-61, 2012.

[3] N. Healy, "Towards a risk-based typology for transnational education education," Higher Education, vol. 69, no. 1, pp. 1-18, 2015.

[4] N. Rawashdeh, T. Tutunji and M. Bani Younis, "Development of a Jordanian-European Double Degree Master Program in Mechatronics Engineering," in 15th International Workshop on Research and Education in Mechatronics (REM), Elgouna, Egypt, 2014.

[5] N. Horishna and H. Slozanska, "Dual degree programmes in social work: is it possible in Ukraine?," Economics and Sociology, vol. 10, no. 2, pp. 165-178, 2017.

[6] T. Barrett, P. Webster, E. Anttila and B. Haseman, "Technology-Enabled Curriculum for Transnational Education in Art History and Theory," International Journal of Education and the Arts, vol. 18, no. 40, 2017.

[7] A. Bilyatdinova, V. Krzhizhanovskaya, A. Boukhanovsky and P. Sloot, "Dutch-Russian Double Degree Master's Program Curricula in Computational Science and High Performance Computing," in Frontiers in Education, Madrid, Spain, 2014.

[8] D. Jacobs, C. Daly, S.-E. Tierney, E. O'Brien and K. Fiebelkorn, "Attitudes and Perceptions of Dual PharmD/MBA Degree Program Students," American Journal of Pharmaceutical Education, vol. 81, no. 4, 2017.

[9] J. Knight, "International universities: Misunderstandings and emerging models?," Journal of Studies in International Education, vol. 19, pp. 107-121, 2015.

[10] Y. Kono, "Opportunities beyond borders: Models of transnational education for U.S. institutions," 3 February 2014. [Online]. Available: https://wenr.wes.org/2014/02/opportunities-beyondborders-models-of-transnational-education-for-u-s-institutions. [Accessed 8 May 2018].

[11] J. Knight, "Transnational Education Remodeled: Toward a Common TNE Framework and Definitions," Journal of Studies in International Education, vol. 20, no. 1, p. 34-47, 2016.

[12] S. Wilkins and J. Huisman, "The international branch campus as transnational strategy in higher education," Higher Education, vol. 64, no. 5, pp. 627-645, 2012.

[13] J. Knight, "Education hubs: A fad, a brand, an innovation?," Journal of Studies in International Education, vol. 15, no. 3, pp. 221-240, 2011.

[14] S. Wilkins, "Ethical issues in transnational higher education: the case of international branch campuses," Studies in Higher Education, vol. 42, no. 8, pp. 1385-1400, 2017.

[15] C. Cronin, "Using case study research as a rigorous form of inquiry," Nurse Researcher, pp. 1927, May 2014.

[16] D. Silverman, Qualitative Research, Sage, 2016.

[17] D. Cobham and K. Jacques, "Constructive alignment: reflections on implementation," in 1st Annual Workshop on Constructive Alignment, Nottingham, 2006.

[18] J. Biggs, Teaching for Quality Learning at University, McGraw Hill, 2003. 
[19] J. Briggs, "Constructive alignment in university teaching," HERDSA Review of Higher, 2014.

[20] D. Cobham and K. Jacques, "Addressing student satisfaction in undergraduate computing programmes: the use of constructive alignment in automating mass, timely and high quality feedback," in 2nd UK Workshop on Constructive Alignment, Nottingham, 2008.

[21] L.-H. Phan, Transnational Education Crossing 'Asia' and 'the West', London: Routledge, 2017.

[22] A. W. Russell, S. Dolnicar and M. Ayoub, "Double degrees: double the trouble or twice the return?," Higher Education, vol. 55, no. 5, pp. 575-591, 2008.

[23] K. Sharpe, "The distinction between academic standards and quality: implications for transnational higher education," Quality in Higher Education, vol. 23, no. 2, pp. 138-152, 2017.

[24] C. Montgomery, "Transnational partnerships in higher education in China: The diversity and complexity of elite strategic alliances," London Review of Education, vol. 14, no. 1, pp. 70-85, 2016. 